\title{
Pattern of childhood tuberculosis among the patients admitted in Dhaka Shishu (Children) Hospital
}

\author{
A T Sultana ${ }^{1}$, R Gathia ${ }^{2}$, M M Huda ${ }^{3}$, J A Begum ${ }^{4}$, Kamruzzaman $^{5}$, M R Amin ${ }^{6}$
}

Abstract

Background: Tuberculosis (TB) poses a serious threat to public health throughout the world but disproportionately afflicts low-income nations. Every year 8.7 million people are affected by TB in the world and six to 10 per cent of them are children.

Objective: The aim of this study was to determine the pattern of childhood tuberculosis (TB) among the patients admitted in Dhaka Shishu (Children) Hospital.

${ }^{1}$ Dr. Akhand Tanzih Sultana Assistant Professor Dept. of Pulmonology Bangladesh Institute of Child Health (BICH), Dhaka Shishu (Children) Hospital

2

Dr. Ribika Gathia

Program Organizer of BRAC DOTS Corner

Dhaka Shishu (Children) Hospital

${ }^{3}$ Dr. Md. Mahmudul Huda

Assistant Professor

Dept. of Pathology

National Medical College Hospital

${ }^{4}$ Dr. Jostna Ara Begum

Associate Professor

Dept. of Pulmonology

BICH \&

Dhaka Shishu (Children) Hospital

${ }^{5}$ Dr. Kamruzzaman

Registrar

Dept. of Pulmonology

Dhaka Shishu (Children) Hospital

${ }^{6}$ Prof. Dr. Md. Ruhul Amin

Professor and head

Dept. of Pulmonology

BICH \&

Dhaka Shishu (Children) Hospital

\section{Correspondence}

Dr. Akhand Tanzih Sultana

Assistant Professor

Dept. of Pulmonology

Bangladesh Institute of Child

Health (BICH), Dhaka Shishu

(Children) Hospital

E-mail:dratsultana@gmail.com

Methods : All inpatient diagnosed TB cases (age 0-15 years) who registered in DOTS clinic of Dhaka Shishu Hospital for treatment of tuberculosis during January, 2015 to December, 2015 were included in this prospective study. Total 91 patients of either sex were enrolled. After taking informed consent data were collected on demographic profile, clinical profile and mortality rate. Data were analyzed in SPSS version 16.

Results : The most common form of TB was EPTB (67.03\%) followed by PTB (32.97\%). The common age group was 1 . 5 years in both extra pulmonary tuberculosis (EPTB) and pulmonary tuberculosis (PTB). Male predominance was seen in (EPTB) cases. EPTB was predominantly meningeal $(27.8 \%)$. Case fatality rate was $14.29 \%$. Mortalities were more common beetween 1.5 years of age and among them 4 were females $(30.77 \%)$ and 9 were males $(69.23 \%)$.Tubercular meningitis (TBM) was the main cause of death which comprised $6.59 \%$.

Conclusion : In this study Tuberculosis was common in younger age. EPTB was common in the children, which was predominantly tubercular meningitis. The majority of mortalities occurred due to tubercular meningitis.

Key Words : Tuberculosis (TB), Pulmonary (PTB), Extra pulmonary (EPTB), Tubercular meningitis (TBM).

Northern International Medical College Journal Vol. 8 No. 02 January 2017, Page 213-215

\section{Introduction}

The World Health Organization (WHO) current estimates in 2015 are that 1 million children currently suffer from Tuberculosis (TB) worldwide ( $<15$ years), and that more than 136,000 die each year. Every day, up to 200 children die from TB though it is a preventable and curable disease. Over half a million children fall ill with TB each year and struggle with treatment. ${ }^{1}$ In high burden TB countries it has been noted that $15-20 \%$ of all TB cases are among children, whereas in low burden TB countries it is estimated that 2-7\% of all TB cases are among children. ${ }^{2}$

The South-East Asia region accounts for a disproportionately high number of global TB cases and Bangladesh is one of 22 'high TBburden' countries. In 2014, there were 187,005 new cases of TB in Bangladesh and it was the leading cause of death, accounting for 81,000 fatalities. Ending the TB epidemic by 2030 is one of the health targets of the newly adopted
Sustainable Development Goals. WHO has set a target for a $95 \%$ reduction in deaths and a $90 \%$ reduction in TB incidence by $2035 .{ }^{3}$

TB remains a major public health problem in Bangladesh. Although there is no estimate on the prevalence of childhood $T B$, it is believed that childhood TB is severely under-diagnosed. ${ }^{4}$ Childhood tuberculosis carries much higher risk of severe disease and death among young children than adults. The management and prevention of TB among children is relatively neglected despite the fact that TB is a cause of significant childhood mortality and morbidity. ${ }^{5}$

Childhood tuberculosis is under-reported in Bangladesh due to difficulties in confirming diagnosis, lack of guidelines for systematic screening, difficulties in referral of suspected childhood TB cases. High prevalence of malnutrition renders the skin test for TB ineffective and lack of laboratory facilities is also an impediment for diagnosis of children. Absence 
of awareness about TB in children also plays a role in the low detection rate of the disease. ${ }^{6}$

WHO recommends that children with TB should be treated and notified through the national TB control programme. ${ }^{7}$ However, studies on epidemiology, clinical profile and diagnostic methods of childhood TB from low-income countries are lacking. In this context this study was carried out to know the recent pattern of childhood TB cases admitted in Dhaka Shishu (Children) Hospital.

\section{Materials and Methods}

All inpatient diagnosed TB cases (age 0-15 years) who registered in DOTS clinic of Dhaka Shishu Hospital for treatment of tuberculosis where National guidelines for the management of tuberculosis in children was followed, during January, 2015 to December, 2015 were included in the study. Total 91 patients of either sex were enrolled in this prospective study. The exclusion criteria were previously treated tuberculosis cases and TB with any other illness. Data were taken using a preformed questionnaire after taking informed consent. From DOTS center data on demographic profile and type of TB on clinical diagnosis were taken. For the purpose of our analysis type of TB was classified as pulmonary TB and extra-pulmonary TB. Mortality data of these TB patients were collected during inpatient management. Ethical clearance was taken from institutional ethical committee. Data was analyzed in SPSS version 16.

\section{Results}

A total 91 patients were diagnosed as tuberculosis in this study period. Age distribution of cases, 19(20.88\%) were within1year, $33(36.26 \%)$ were between 1 to 5 years, 27(29.67\%) were 6 to 10years, $12(13.19 \%)$ was above 10 years of age. EPTB were more in $<1-5$ years but least in $>10$ year age group. (Table-I)

\section{Table I : Distribution of age of study population $(n=91)$}

$\begin{array}{ccccc}\text { Age (years) } & \text { PTB } & \text { EPTB } & \text { Total } & \text { Percentage \% } \\ <1 & 7(36.8 \%) & 12(63.2 \%) & 19 & 20.9 \\ 1-5 & 8(24.3 \%) & 25(75.8 \%) & 33 & 36.3 \\ 6-10 & 9(33.3 \%) & 18(66.7 \%) & 27 & 29.7 \\ >10 & 6(50 \%) & 6(50 \%) & 12 & 13.1 \\ \text { Total } & 30 & 61 & 91 & 100\end{array}$

There was a male preponderance. Male were 48(52.7\%) and female were $43(47.3 \%$ ). (Fig-1)

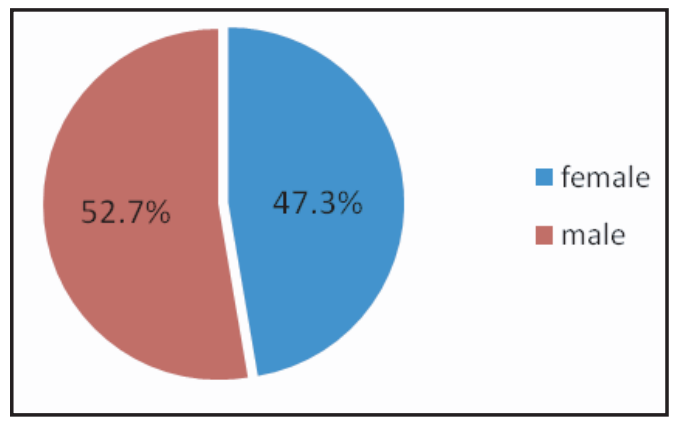

Fig 1: Sex distribution of the studied children
All of the patients were BCG vaccinated according to EPI schedule. Most common form of TB was extrapulmonary TB (61cases, 67.03\%) followed by pulmonary TB (30cases, $32.97 \%)$. (Fig-2)

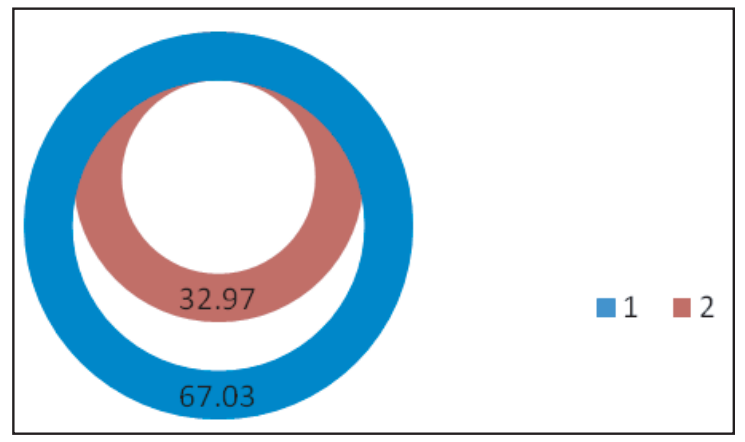

Fig 2: Pattern of tuberculosis in the studied children

Among 61 patients of extrapulmonary TB, 36(59.02\%) were male and $25(40.98 \%$ ) were female. But in case of pulmonary TB, $19(63.33 \%)$ were female and $11(36.67 \%)$ were male. (Table-II)

Table II : Distribution of sex of tuberculosis cases

$\begin{array}{lcc}\text { Sex } & \text { PTB } & \text { EPTB } \\ \text { Male } & 11(36.67 \%) & 36(59.02 \%) \\ \text { Female } & 19(63.33 \%) & 25(40.98 \%) \\ \text { Total } & 30 & 61\end{array}$

The majority of EPTB cases involved the meninges i.e. tubercular meningitis which comprised $27.87 \%$ of total EPTB cases. This was followed by TB lymphadenitis (24.60\%), military TB (16.39\%), pleural effusion (14.75\%), abdominal TB (14.75\%) and spine TB (1.64\%). (Fig 3)

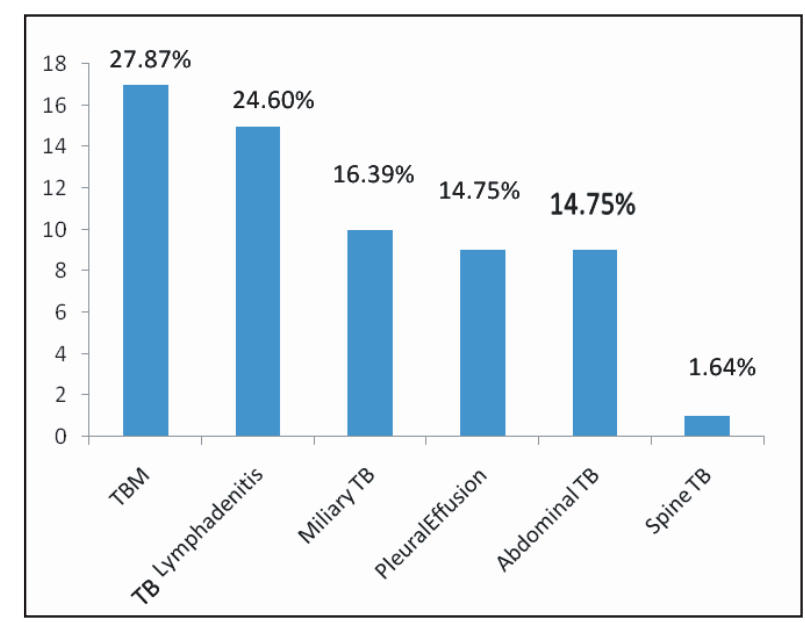

Fig 3: Pattern of extrapulmonary tuberculosis in the studied children

Among 91 tubercular patients 13 were died. Therefore in this study case fatality rate was $14.29 \%$.Most of them were within 15 years of age. TBM involved the main bulk of mortality which comprised $6.59 \%$ of total death cases. (Table III) 


\begin{tabular}{|c|c|c|c|c|c|c|}
\hline \multicolumn{2}{|c|}{ Age (years) } & \multicolumn{2}{|c|}{ Types of TB } & & \multirow[t]{2}{*}{ Number } & \multirow[t]{2}{*}{ Percentage } \\
\hline & TBM & Miliary TB & PTB & Pleural effusion & & \\
\hline$<1$ & 03 & 00 & 02 & 00 & 05 & 38.47 \\
\hline $1-5$ & 03 & 02 & 00 & 01 & 06 & 46.15 \\
\hline $6-10$ & 00 & 01 & 00 & 00 & 01 & 7.69 \\
\hline$>10$ & 00 & 00 & 01 & 00 & 01 & 7.69 \\
\hline Total & 06 & 03 & 03 & 01 & 13 & 100 \\
\hline
\end{tabular}

Discussion

This study was done to identify the different types of tuberculosis among children attending Dhaka Shishu Hospital.

In our study a total of 91 patients were included. The most common age group of both PTB and EPTB were 1-5 years. Male sex predominance was seen in extra pulmonary TB but female were more affected in case of PTB. Similar epidemiological profile were found in other study done in India ${ }^{8}$ But in the study of Shafi Ullah, the overall male: female ratio was $1: 2$; that was also found in several other studies. ${ }^{9}$

In our study most common form of TB was extra pulmonary TB (61cases, 67.03\%) followed by pulmonary TB (30cases, $32.97 \%$ ) age group was 1-5 yr. Study done by Phongsamart W et all showed that young children are more likely to develop extra-pulmonary TB. ${ }^{10}$ A study in Nepal, showed $55 \%$ of all TB patients had extra-pulmonary involvement and 10/12 patients of disseminated or miliary TB were younger than 10 years and most of the children who had extra-pulmonary TB were older than 4 years. ${ }^{11} \mathrm{~A}$ study done in Addis Ababa is comparable with our study. ${ }^{12}$ On the other hand WHO reported in $201470-80 \%$ of children with TB in their lungs (pulmonary TB) and the rest extra pulmonary TB. ${ }^{13}$

In this study majority of EPTB cases were tubercular meningitis which comprised $27.87 \%$. A recent studies from China reported the incidence of $\mathrm{TB}$ meningitis as $38.8 \%$ in $\mathrm{TB}^{14}$ Infants and young children are more likely than older children and adults to develop life-threatening forms of TB disease (i.e., disseminated TB and TB meningitis), and because of their age, pediatric TB acts as a surrogate for identifying recent transmission. ${ }^{15}$

In this study case fatality rate was (13 cases) $14.29 \%$. The mortality rate in this study is comparable to the mortality rate of Tanzania (10.9\%). ${ }^{16}$ The most common cause was tuberculous meningitis(46.1\%) and age group was 1-5 years. Drobac PC et al Found that among disease localizations, high mortality was seen with meningitis (28.4\%). In high-burden countries a considerable proportion of TB patients are children and TB related morbidity and mortality is high among children. ${ }^{17}$

\section{Conclusion}

In this study we found that extra pulmonary tuberculosis was more than PTB. Among EPTB tubercular meningitis (TBM) was the commonest in case of children. The majority of mortalities occur in TBM cases.

\section{References}

1. World Health Organization. Global tuberculosis control: surveillance, planning, financing. Geneva: WHO, 2008. http://whqlibdoc.who.int/ publications/ 2008/9789241563543_eng.pdf

2. Childhood Tuberculosis Roadmap", 11th November 2012 www.stoptb.org

3. WORLD TB DAY 2016: Bangladesh continues its battle against the disease SEARO | Bangladesh. www.who.int

4. Scaling up of management of childhood tuberculosis in Bangladesh, USAID, Research Areas >> Disease Control Tuberculosis www.tractionproject.org/

5. Tsai K, Chang H, Chien S, Chen K, Mai M. Childhood Tuberculosis: Epidemiology, Diagnosis, Treatment, and Vaccination. Pediatr Neonatol 2013; 54 (5): 295-302.

6. Mohamed R Karim et al. Risk factors of childhood tuberculosis, WHO SouthEast Asia Journal of Public Health 2012;1(1):76-84.

7. World Health Organization.Global tuberculosiscontrol: epidemiology,strategy, financing:WHO report 2009. Geneva: WHO, 2009.http://whqlibdoc.who.int/ publications/2009/9789241563802 _eng.

8. Jain SK, Ordonez A,Kinikar A, Gupte $N$, Thakar M, Mave $V$, Jubulis J,Dharmshale S, Desai S, Hatolkar S, Kagal A, Lalvani A, Gupta A,Bharadwaj R. Pediatric Tuberculosis in Young Children in India: A Prospective Study. BioMed Research International. https://www.hindawi. Com/journals/ bmri/2013/783698

9. Ullah S, Shah SH, Rehman AU, Kamal A, Begum N. Tuberculous lymphadenitis in afghan refugees. J Ayub Med Coll Abbottabad 2002; 14(2):22-23.

10. Phongsamart W, Kitai I, Gardam M, Wang J, Khan K. A population-based study of tuberculosis in children and adolescents in Ontario. Pediatr Infect Dis ] 2009; 28 (5): 416-9

11. Sreeramareddy CT, Ramakrishnareddy N, Shah RK, Baniya R, Swain PK. Clinico-epidemiological profile and diagnostic procedures of pediatric tuberculosis in a tertiary care hospital of western Nepal-a case-series analysis. BMC Pediatrics201010: 57 DOI: 10.1186/1471-2431-10-57

12. Hailu D, Abegaz WE, Belay M.Childhood tuberculosis and its treatment outcomes in Addis Ababa: a 5 -years retrospective study. BMC Pediatrics2014; $14: 61$

13. Childhood TB: Training Toolkit", WHO, Geneva, 2014 www.who.int/tb/ challenges/childtbtraining

14. Wu XR, Yin $\mathrm{QQ}$, Jiao $\mathrm{AX}$, et al. Pediatric tuberculosis at Beijing Children's Hospital: 2002-2010.Pediatrics. 2012; 130(6):1433-40

15. Batra S, Ayaz A, Murtaza A, Ahmad S, Hasan R, Pfau R. Childhood tuberculosis in household contacts of newly diagnosed TB patients. PLOS One. 2012; 7:e40880. http://dx.doi.org/10.1371/journal.pone.0040880

16. Mtabho CM, Irongo CF, Boeree MJ, Aarnoutse RE, Kibiki GS: Childhood Tuberculosis in the Kilimanjaro region: lessons from and for the TB Programme. Trop Med Int Health 2010, 15 (5): 496-501

17. Drobac PC, Shin SS, Humani P, Atwood S, Furin J, Franke MF, Lastimoso C,Castillo H.Risk Factors for In-Hospital Mortality Among Children With 